of the ubiquitous pilferer. In a metre bridge set-up, for example, most of the components have substantial 'black-market' value, and unless precautions are taken to safeguard the apparatus there is a high probability that it will be found one morning in a somewhat despoiled state. Experience has similarly shown the extreme undesirability of leaving electric lamps in accessible positions.

Considerable progress has been made in building up the library again, but little can be done to improve the text-book situation. In the Western Zones of Germany there is no paper available for the printing of scientific books, although the position of journals is slightly better. The Zeitschrift für Physik, for example, has just reappeared under the editorship of von Laue. A few copies of British and American scientific periodicals have found their way into the library, but the impossibility of payment prevents a regular influx of foreign literature.

Similar conditions are encountered at the Heinrich Hertz Institut für Schwingungsforschung, which is associated with the Technical University by virtue of the fact that its director, Prof. G. Leithäuser, is a member of the staff, and of the senate, of the University. This Institute is concerned with the training of engineers in radio communications and allied fields, and possesses facilities for a small amount of research. All work is, of course, subject to the usual Military Government serutiny, and no micro-wave equipment is allowed. Suitable apparatus for teaching purposes is in very short supply and the number of available experiments is thus severely limited; one class of twenty-four students is obliged to work in groups of six as there is sufficient apparatus for only four experiments. The main lines of research are : defects of mirror systems, the design of large horn loudspeakers for low-frequency reproduction and various radio circuit problems. A pulsed transmitter (wavelength range $30-100$ metres) is being designed for ionospheric investigations.

So far as research in physics is concerned, facilities at the Technical University are practically nonexistent, and of the three professors, C. Ramsauer, H. Kallmann and R. Frerichs, the two latter are supervising small groups working at the Kaiser Wilhelm Institut in Dahlem. This is situated in the American sector and therefore all projects are submitted to the American authorities for approval. Prof. Kallmann, in addition to theoretical work in wave mechanics, is working on the detection of $\alpha$ - and $\beta$-particles by a scintillation method, using organic fluorescent materials. The scintillations are recorded by a photo-tube and the responses are amplified and shown on a cathode-ray oscillograph. Prof. Frerichs is investigating the properties of cadmium sulphide photo-cells embodying photo-conducting strips about $1 \mathrm{~cm}$. in length. Interesting results have been obtained with $\beta$ - and $\gamma$-radiation, and further experiments are being carried out with $\mathrm{X}$-rays.

As a concluding remark, it may perhaps be appro. priate to mention one of the most notable features of academic life, namely, the universal eagerness for contact with the world outside Germany and in particular with Great Britain. There are many reasons why such schemes as student exchanges can take place on only a small scale at present; but a few students and lecturers from Germany have already visited Great Britain under the auspices of the International Student Service, and it is to be hoped that many other visits of this nature will be made possible in the future.

\section{German Physical Society in the British Zone}

\section{Autumn Conference}

A $\mathrm{N}$ autumn conference of the German Physical Society in the British Zone was held during September 5-7 in the University of Göttingen. This conference gave striking evidence of German recuperative powers under considerable material diff. culties, for it was attended by some five hundred physicists, and a formidable total of fifty-eight original papers was read. The conference was declared open by the president, Max v. Laue, and at this opening session the assembled members and visitors were greeted by Dr. R. Fraser on behalf of the Research Branch of the C.C.G. Although technically a British Zonal conference, in effect it was to some extent a meeting of the Physical Society for the whole of Germany, since delegates were also present from the French, Russian and American Zones. The younger genera,tion was strongly represented and actively contributed, a fact calling forth the approval of many of the older German physicists. There is no doubt that organised physics in Germany has now recovered from the stagnant aftermath which followed defeat, and active research is being prosecuted from many centres.

Considerable satisfaction was expressed by many Germans present at the fact that a number of invited guests had arrived from abroad to read papers. These were : A. Michels (Amsterdam), V. L. Jordan (Copenhagen), B. Pippard, E. H. Sondheimer, D. Shoenberg (Cambridge), S. Tolansky (London), J. G. Wilson (Manchester), and all were received with warmth and given a particularly attentive hearing. The number of papers read was sufficiently large to enable the emerging pattern of interests in the post-war physics of Germany to be appreciated. Nuclear physics (in the wide sense) accounted for fifteen contributions divided into cosmic rays (5), nuclear reactions (5) and isotopes (5). There were nine papers on optics and spectroscopy, nine on metallic conduction and magnetism, and nine on acoustics. The remaining sixteen papers ranged widely, from quantum mechanics to diffusion pumps.

It will be gathered from this distribution that the pattern of interests is little different from what might have been expected from any German conference of pre-war days, and indeed the traditional emphasis so characteristic of Germany is well reflected. A matter of some considerable interest is the emergence of quite a number of unfamiliar place names as the centres of research. This may possibly be associated with war-time evacuation measures carried out to avoid the intensive bombing attacks, or perhaps for other reasons. In addition to many contributions from old-established and well-known university centres, papers were read about researches which had been carried out in such unfamiliar places as, for example, Hechingen, Weissenau, Tailfingen, Honnef, Horb, Markenkirchen, etc. It is stressed that these contributions were largely of the academic type normally expected from universities or associated establishments.

On each of the three days of the conference, a general review of a specific topic was given; these aroused a good deal of interest. The first, which constituted the opening paper of the conference, was delivered by W. Heisenberg. It was a clear and concise factual statement of the present position in 
cosmic ray research, and was a valuable and comprehensive contribution. The second general review was by $\mathbf{K}$. Wirtz. The author was a member of a research team engaged on the German uranium project, and in his paper he surveyed the limited achievements of the Germans in this direction. The third general paper was delivered by E. Meyer, who surveyed recent developments in acoustics in a comprehensive manner.

In addition to the formal papers read, some specially arranged symposia were held, the visitors from Britain taking part respectively in those on metallic conduction and interferometry. The social programme was indifferent, which was inevitable in view of the difficult conditions in Germany to-day. In view of these quite serious difficulties, the conference must undoubtedly be considered as quite an administrative achievement and augurs well for the future of physical research in Germany, despite the very serious shortage in the current materials of research.

S. 'Tolansky

\section{Statistical Methods}

$\mathrm{T}$ HE first meeting of mathematical statisticians ever held in Germany took place on September $3-4,1947$, in Göttingen. It was attended by British statisticians who had been invited in an endeavour to overcome the difficulties which German mathematicians have experienced by having been cut off from foreign literature for a long time. The losses suffered by libraries in Germany and the impossibility of replacing their stocks contribute to the desire of German scientific workers to resume personal relations with British (or other) contemporaries.

The first meeting was opened by Dr. H. Münzner, professor of theoretical statistics in the University of Göttingen. Prof. P. Riebesell (Hamburg) then gave a critical account of the methods of Grosszahlforschung, showing that this version of the statistical analysis of mass production is either trivial or false. $\mathrm{He}$ discussed the rolation of the normal curve to empirical distributions and suggested a test of the significance of two or more observational modes based on the idea of confidence limits (Mutungsbereich). S. Vajda (London) gave a talk on "The Algebraic Basis of the Analysis of Variance Method" in which he derived well-known formulæ for the tests of effects and interactions of any order by the use of orthogonal polynomials, and pointed out how various possible but different definitions of effects were due to different algebraic constructions (see Nature July 5, p. 27.)

In the afternoon, Miss M. P. Geppert (Kerckhoff Institute, Bad Nauheim) proved by examples that in estimating a parameter from a sample none of the three central measures, mode, mean, or median, of the fiducial distribution needs coincide with the maximum likelihood estimate. Prof. O. N. Anderson (late of Sofia, now at the University of Munich) gave an account of the probloms of inverse probability and fiducial limits, stressing the necessity for deriving formulæ pertinent to a model "without replacement"; he also discussed a formula which should take the place of the $t$-distribution in the case of relative frequencies (which are not normally distributed) for small $n$ and $p \neq(1-p)$.

On September 4, H. L. Seal (London) spoke on non-parametric tests and discussed some of them from the point of view of errors of the first and second kind. Prof. H. Münzner (Göttingen) introduced and solved an integro-difference equation which arises in the description of a 'cascade'-process where a particle multiplies $k$-fold, with probabilities dependent on $k$, at times $t$, the "intensity of multiplication" being dependent on $t$. Finally, Dr. E. Sperner (Oberwolfach) gave an account of his method of expanding meteorological functions in terms of eigenfunctions for the purpose of extrapolation.

An animated discussion took place in the afternoon at the Geophysical Institute, where the participants met by courtesy of the director, Prof. J. Bartels, whose notion of "persistence tendency" applied to time series (see J. Amer. Stat. Assoc., June, 1940) gave rise to talks on a great variety of subjects, ranging from weather forecasts to the Heligoland explosion (see Nature, September 13, p. 350), seismic graphs of which were exhibited.

Many representatives of German statistics were, of course, unable to attend the meeting, but there was much interest in its proceedings. It was felt by all that the comparison of results obtained in ignorance of similar work done in other countries may prove stimulating, though at present Germany has scarcely anything to show which could compare with the fundamental progress achieved in Great Britain and the United States in the last twenty-five years or so. To facilitate the exchange of ideas it was decided to start work on an English-German dictionary of statistical terms, and to supplement it with proposals for a universal notation. Suggestions will be weleorned by Prof. H. Münzner (University of Göttingen, Germany, British Zone), or by the British visitors to the meeting.

S. VAJDA

\section{Petroleum Geology}

$\mathrm{F}$ OR the first time in the course of fifteen years, a meeting of those interested in oil geology was held in Hanover during September 9-11, about five hundred geologists and geophysicists being present. The State Secretaries of the administrative province, representatives of the Military Government, and numerous foreign guests were welcomed by Prof. Bentz, director of the Oil Department of the Reichsamt für Bodenforschung.

During the last fifteen years, several thousand wells have been drilled in north-western Germany, which have considerably increased the theoretical and practical information about the deep subsurface. The main part of the meeting consisted of reports from twenty-six German oil-fields. Their exploration by means of the most up-to-date methods has not only increased the production of the oil industry considerably but also provided much geological and geophysical material, which has helped to clarify the complicated tectonic, stratigraphic and facial conditions of the north-west German Saxonicum. Of the numerous Mesozoic rocks with oil-bearing possibilities from which the production of the north-west German oil-fields is derived, preference is still given to the Zechstein as the source rock of the oil ; this hypothesis, however, was by no means placed in the foreground as the only one. The German oil industry owes its successes to this positive scientific attitude. It is only necessary to mention here the importance of the Ems district for German economic life. With regard to its reserves, this district is among the most important German oil provinces and is thus also an important political factor. 